Goldschmidt 2021 Abstract

https://doi.org/10.7185/gold2021.5422

\section{Geochemical studies of rock paintings in Serranía de La Lindosa of Colombia as an input for cultural management in this area}

\section{JUDITH TRUJILLO}

Universidad de Los Andes, Corporación Gipri

Presenting Author: j.trujillo@uniandes.edu.co

Given the growing interest of the history of the settlement and the cultures that inhabited the Amazon, in recent years, various archaeologists have been engaged with greater intensity in these investigations and have been expanding their studies with the support of basic sciences to characterize the sites and thus determine with greater precision the pigments and their cultural uses. This work attempts to synthesize the history of such efforts in a new stage that links different areas of knowledge. From this perspective, between 2016 and 2018, a multidisciplinary study of the indigenous rock paintings of Serranía de La Lindosa, in the south east of Colombia, was developed. This research group included the participation of anthropologists, archaeologists, biologists, chemists and photographers from the Indigenous Rock Art Research Group (GIPRI) and geologists and archeometrists from the Economic Geology and Applied Mineralogy Study Group of the Universidad Nacional of Colombia (GEGEMA), who from each of their disciplines, contributed their knowledge to the study of these aesthetic manifestations of Colombian and humanity heritage. From geochemistry and with the help of analytical techniques, the mineralogical composition of the pigments that make up the paintings, the rocky substrate and certain types of deterioration that affect their conservation were identified. In this way, providing important information about the knowledge, management and use of the landscape and its resources, of the aboriginal communities that had made of such pictographs. These results were shared with the local community, which is searching in promoting responsible tourism to these sites. Their interest arises from looking for new economic alternatives that give them the possibility of leaving their previous activities related to illegal coca crops. This new perspective comes out as a commitment to the peace processes that are being developed in the country and thus stop the war that for more than 50 years generated unbridled violence in these areas.
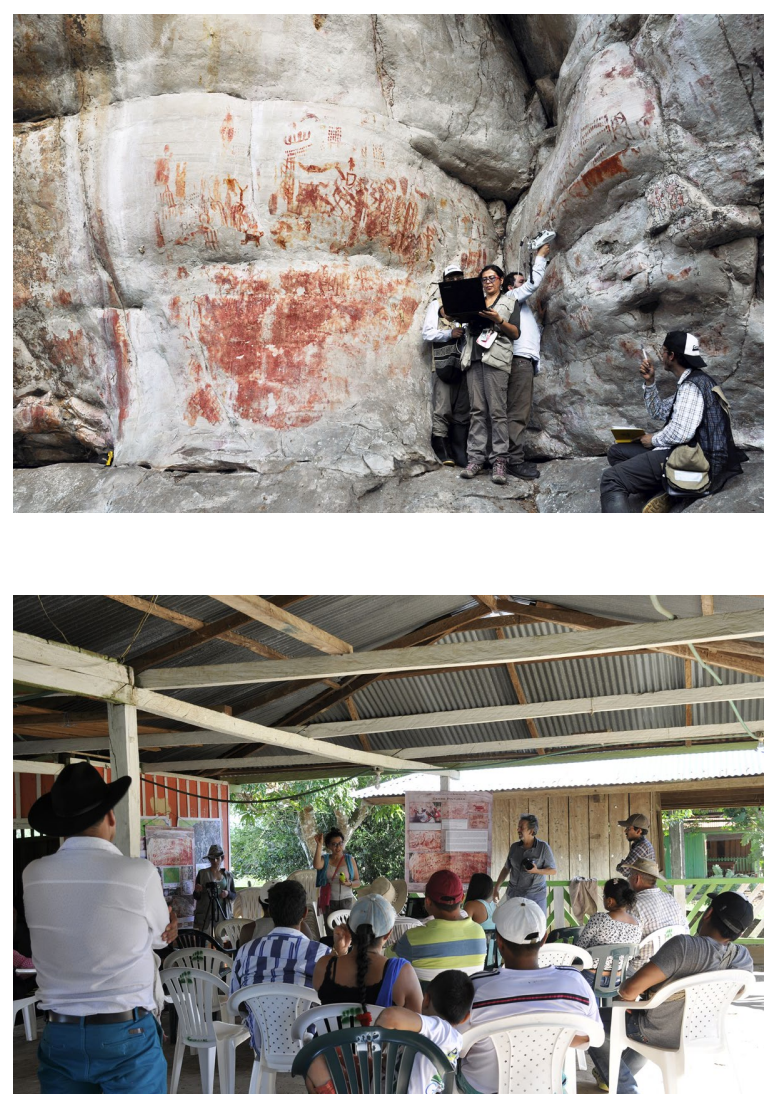